UCRL-JC-116021

PREPRINT

\title{
Nanostethoscopy: A New Mode of Operation of the Atomic Force Microscope
}

\author{
A. Keaton, J.F. Holzrichter, R. Balhorn, and W.J. Siekaus
}

This paper was prepared for submittal to the Nato Advanced Study Institute Conference Schluchsee, Germany March 7-18, 1994 and to Forces in Scanning Method Probe Nato ASI Services, Kluwer

February 1994

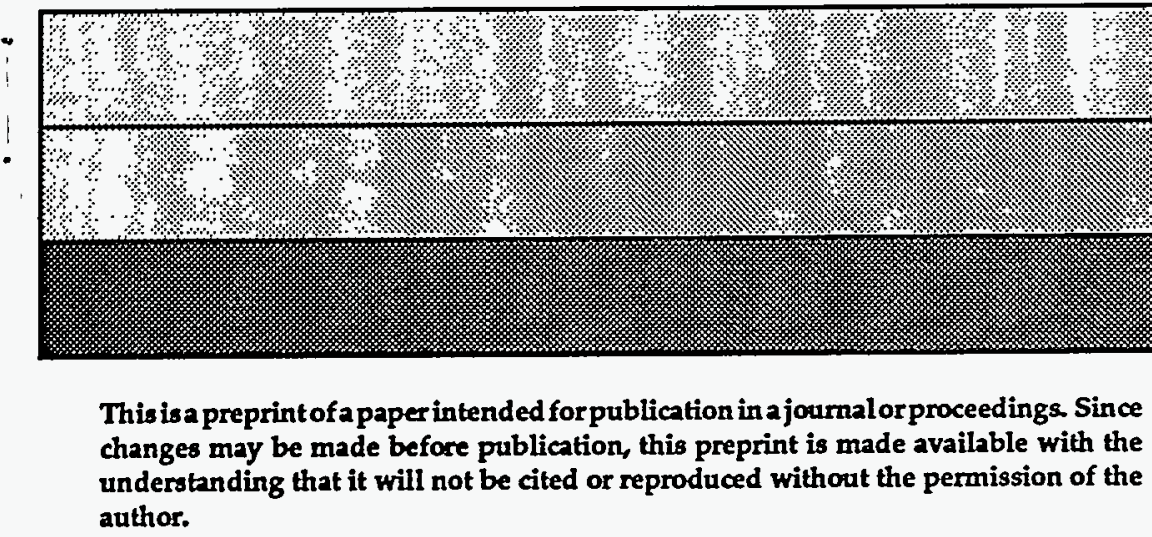
understanding that it will not be cited or reproduced without the permission of the author. 


\section{DISCLAIMER}

This report was prepared as an account of work sponsored by an agency of the United States Government. Neither the United States Government nor any agency thereof, nor any of their employees, make any warranty, express or implied, or assumes any legal liability or responsibility for the accuracy, completeness, or usefulness of any information, apparatus, product, or process disclosed, or represents that its use would not infringe privately owned rights. Reference herein to any specific commercial product, process, or service by trade name, trademark, manufacturer, or otherwise does not necessarily constitute or imply its endorsement, recommendation, or favoring by the United States Government or any agency thereof. The views and opinions of authors expressed herein do not necessarily state or reflect those of the United States Government or any agency thereof. 


\section{DISCLAIMER}

Portions of this document may be illegible in electronic image products. Images are produced from the best available original document. 


\title{
NANOSTETHOSCOPY: A NEW MODE OF OPERATION OF THE ATOMIC FORCE MICROSCOPE
}

\author{
A. KEATON. J.F. HOLZRICHTER, R. BALHORN and \\ W.J. SIEKHAUS \\ Lawrence Livermore National Laboraton \\ P.O. Box 808 \\ Livermore, CA 94550 \\ USA
}

\begin{abstract}
We introduce a new mode of operation of the atomic force microscope (AFM). This detection scheme. a "Nano-Stethoscope". involves using the atomic force microscope in a novel acoustic mode not generally recognized. The Nano-Stethoscope uses the conventional scanning feature to locate a desired site. positions the AFM microscope tip over the site. holds the cantilever stationary (in $x$ and $y$ ) and records the tip's z-motion as a function of time. The tip/cantilever system thus functions as a micro-motion detector to respond to characteristic "pulsations". nano-configurational changes. or any other event that influences the position of the tip as a function of time. We have demonstrated the feasibility of using the tip of an AFM in this manner in a biological system with a measurement of the vibrations of an emerging shrimp egg nauplius $(-3 \mu \mathrm{m},-10 \mathrm{~Hz})$ and on the Ȧngstrom scale in a nonbiological system i.e.. the thermal expansion of metal interconnect lines on a microelectronic circuit.
\end{abstract}

\section{Introduction}

The atomic force microscope has been used in the constant-force. scanning mode to measure the shapes of many biological molecules. including DNA 1234567891011 121314151617181920212223 . A problem with conventional AFM approaches is that the radius of curvature of even the best AFM tips interferes with identification of DNA bases. A number of groups. including ours at LLNL 51724 , and our collaborators in Munich 25 have attempted to sequence DNA by resolving individual bases in tunneling images. These workers have had some isolated successes. but the normal process of rasterscanning the microscope tip across the DNA molecules causes them to move out of the scan area. In addition. the poor conductivity and surface adhesion of the DNA preclude observation of the bases attached to the phosphate backbone.

We have begun to use 26 a stationary probe microscope in a new mode to measure the "wing" beating of a nauplius as it emerges from a shrimp egg with micron resolution at a beat frequency of $\sim 10 \mathrm{~Hz}$. In this mode. after locating and stabilizing the tip on the object of interest. the AFM tip remains stationary in the xy plane and measures characteristic motions of the object in the vertical direction. This mode can be use to provide important information on a wide variety of systems (biological. micromechanical, microelectronic. etc.). 
An advantage of the time-domain mode of operation is the stationary aspect which reduces (but does not eliminate) perturbations on the sample due to the presence of the tip. In the conventional mode. the scanning process usually moves molecules about on the substrate. possibly deforming them: this effect has been specifically identified as the leading cause of irreproducibility in AFM imaging of DNA 27 .

The use of the AFM in the time-domain mode places special requirements on the AFM system. especially for submicron objects. In particular, both scanning and stationary operations are required. The scanning mode is used for object location. tip placement. and "station-keeping". The stationary mode provides information on the vertical cantilever position (which reflects the object motion) as a function of time. The mechanics of the tip-cantilever-operating fluid or the coupled tip-cantilever-object determine the operational range of the instrument. Three important parameters determined by the instrument mechanics are the time response. object deformation. and vertical position resolution. Thermal noise ultimately limits the minimum detectable force and the subsequent minimal detectable conformational response of the object. Other important influences on the system sensitivity are associated with the operating medium. In a liquid medium. inertial and viscous forces are negligible $\left(10^{-18} \mathrm{~N}\right.$ and $10^{-15} \mathrm{~N}$. respectively) because the tip velocity is so low (e.g. $10^{-8} \mathrm{~m} / \mathrm{s}$ ). but micro-turbulence in the liquid environment associated with laser sensing of the cantilever deflection is noticeable. In measuring electrically active systems. electrostatic and electromagnetic pick-up must be prevented. In an air environment. extraneous forces associated with humidity-induced surface layers and static electricity must be addressed.

\section{Experimental}

For our experiments. we use a Digital Instruments Nanoscope III system which provides time-domain readout. A suitable cantilever (Digital Instruments) for these experiments has a spring constant of $0.1 \mathrm{~N} / \mathrm{m}$ (resulting in a force on the object of $10 \mathrm{pN}$ per $\AA$ deflection) and a resonant frequency of $10.000 \mathrm{~Hz}$. The mechanics for these systems have been optimized for the scanning application.

\subsection{VIBRATIONS OF EMERGING SHRIMP EGG NAUPLIUS}

Brine shrimp artemia cysts (San Francisco Bay) commercially packaged for growth as aquarium fish food were placed onto a circular microscope slide which formed the bottom of a fluid cell of an atomic force microscope. Commercial salt (rocksalt. Leslie Salt Company) solution ( $0.27 \mathrm{M}$ ) was supplied to the cell with syringes, and new solution was added to the cell once an hour.

\subsection{MECHANICAL VIBRATIONS}

Figure 1 shows a schematic drawing of the microelectronic circuit fabricated on a silicon chip and associated electronics for generating Angstrom scale mechanical vibrations. The circuit has a pattern of three gold lines on its surface. each of which has "wide" and "narrow" sections. The "narrow" sections are $50 \mu \mathrm{m}$ long with a cross-section of $1 \mu \mathrm{m}^{2}$ : the "wide" sections have a cross-section of $25 \mu \mathrm{m}^{2}$. The "wide" sections of the gold lines 
are connected to an external electronic circuit synchronized with the scan of the NanoStethoscope and capable of generating square wave pulses of different duration. amplitude. and delay with respect to the synchronization signals. The chip was mounted in the NanoStethoscope and imaged using the conventional scanning mode to find the location at which to monitor the thermal expansion.

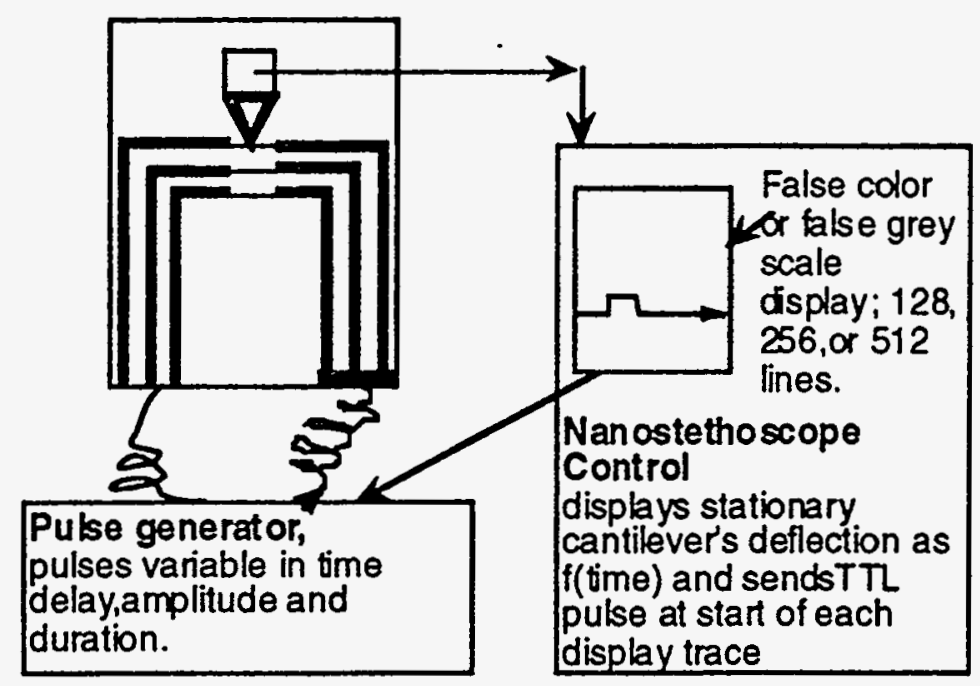

Figure 1. Schematic diagram of surface of microelectronic circuit and associated electronics for generating Ångstrom scale mechanical vibrations.

Micron-size metallic interconnect lines in electronic circuits are heated by the electric current passing through them and expand due to their thermal expansion coefficient $\left(-1.4 \times 10^{-5} /{ }^{\circ} \mathrm{C}\right.$ for gold). For example. a circuit of $1 \mu \mathrm{m}$ height expands by $0.14 \mathrm{~nm}$ when its temperature rises by $10^{\circ} \mathrm{C}$. Adiabatic calculations predict that at a current of $\sim 3 \mathrm{~mA}$. the temperature of each gold line should reach $25^{\circ} \mathrm{C}$ in $-5 \mathrm{msec}$. Hence frequencies up to $1 \mathrm{kHz}$ can be investigated. This frequency range is well within the capability of the Nano-Stethoscope's electronics.

\section{Results}

\subsection{SHRIMP EGG NAUPLIUS}

The tip of the AFM was placed onto a particular shrimp cyst and images of the shell were taken. An image of the cracking of the shell is presented in Fig. 2(a). 


\section{$417 \mathrm{~nm}$}

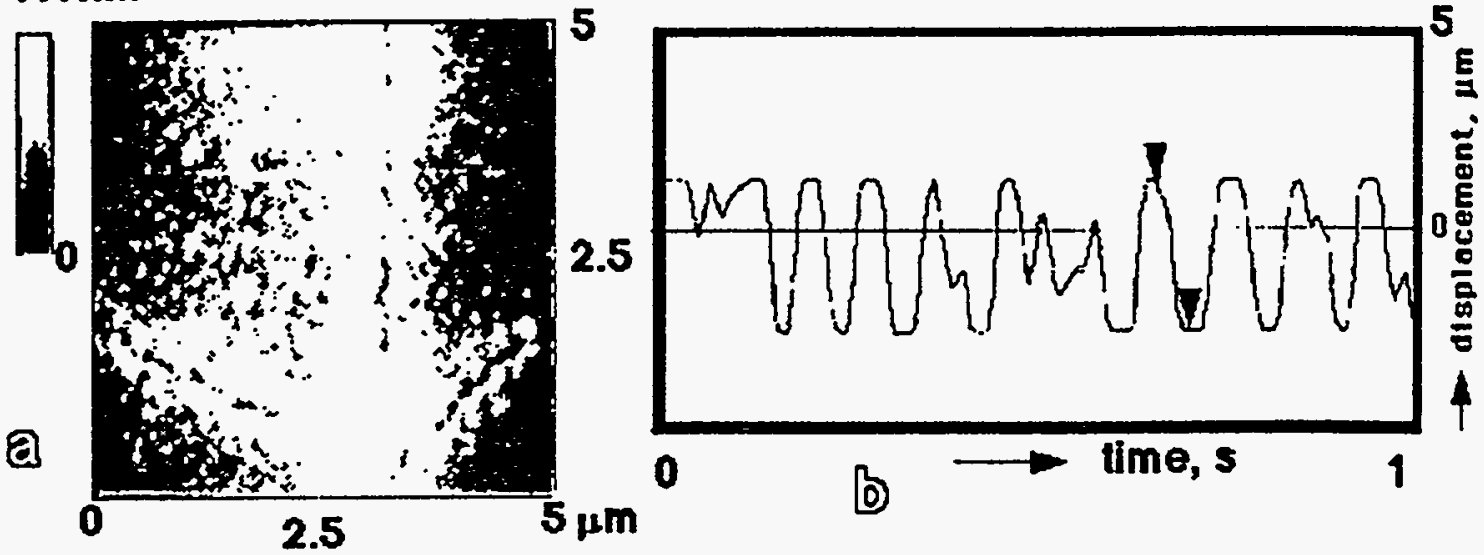

Figure 2. (a) AFM image of shrimp cyst cracking in brine solution. (b) NanoStethoscope trace of nauplius's "wing beating" as it emerges from crack. Amplitude $-3.4 \mu \mathrm{m}$ : frequency $\sim 10 \mathrm{~Hz}$.

After the E1 pre-nauplius stage was formed. the tip was repositioned onto a location behind the right eye-spot and held stationary in that position. After -3 hours. just before leaving the shell in the E2 stage. strong pulsations (amplitude $\sim 3.4 \mu \mathrm{m}$ : frequency $\sim 10 \mathrm{~Hz}$ ). shown in Fig. 1(b). were observed. These data demonstrate that the Nano-Stethoscope can be used to determine the location. time of development. amplitude. and frequency of vibrations occurring in a living biological entity.

\subsection{MICROELECTRONIC CIRCUIT}

The response of the Nano-Stethoscope was tested using the described electronic circuit with pulse amplitudes from $100-300 \mathrm{mV}$ and durations of $2-80 \mathrm{~ms}$. Pulses of $300 \mathrm{mV}$ are expected to raise the temperature of the circuit a few tens of degrees Celsius. Figure 3(a) shows the unfiltered/unprocessed response of the Nano-Stethoscope to a pulse of approximately $2 \mathrm{~ms}$ duration. The system clearly has a frequency response sufficient to show a sharp rise time of the pulse. Despite the non-optimized noise protection. an amplitude increase of $\sim 6 \dot{A}$. corresponding to a $40^{\circ} \mathrm{C}$ temperature rise. is seen in Fig. 3(b). The detection limit in this experimental setup was found to be at pulses of $-100 \mathrm{mV}$. 

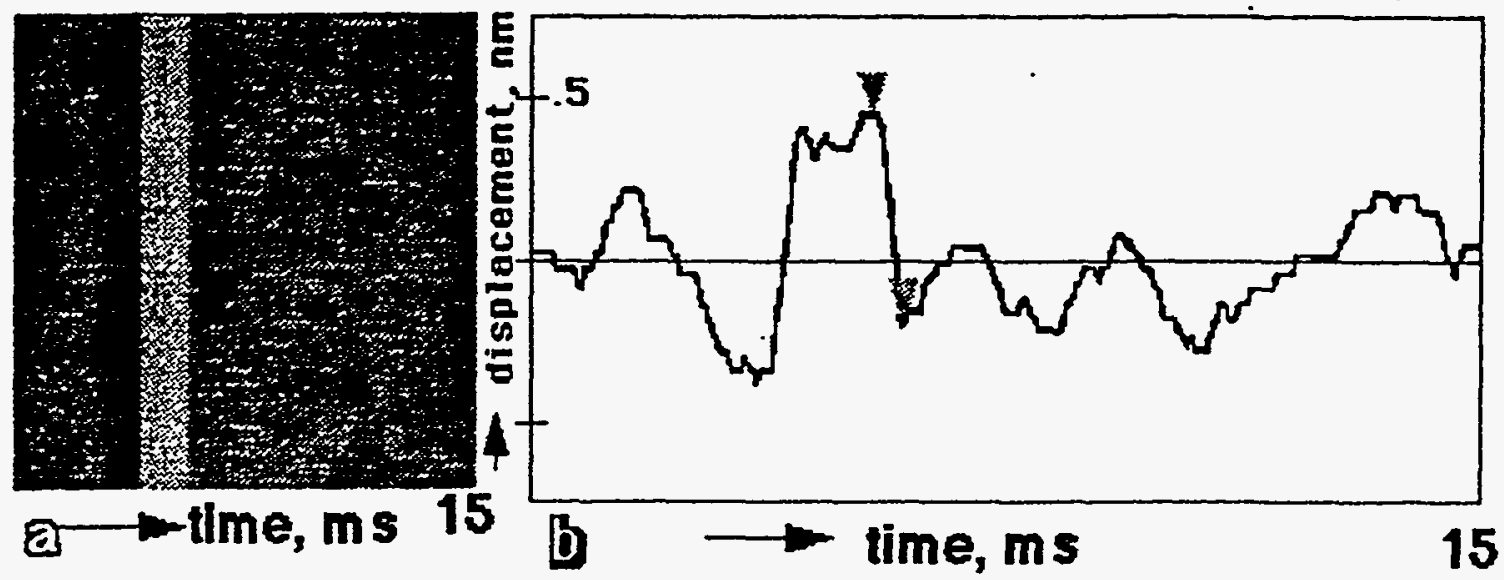

Figure 3. (a) False gray scale image of cantilever displacement (thermal expansion) as a function of time for a $300 \mathrm{mV} .2 \mathrm{~ms}$ pulse. 256 consecutive lines are shown. (b) Section along horizontal line showing a displacement of $0.648 \mathrm{~nm}$ to temperature of $\sim 40^{\circ} \mathrm{C}$.

Figure 4 shows a sequence of cantilever displacement images in which pulses of 300.100. and $200 \mathrm{mV}$ are applied. The vertical bar is distinctly visible for the higher voltages. and only faintly visible (in the original data) for $100 \mathrm{mV}$ pulses. Since the deposited power (and hence the expected temperature rise and thermal expansion) is proportional to $V^{2} / R$ (where $\mathrm{V}$ is voltage and $\mathrm{R}$ is resistance). it appears that a cantilever deflection of approximately $0.8 \AA$ is faintly detectable even in this non-optimized experimental setup with a high noise level arising from the multitude of electronic devices and cables attached to the cell of the Nano-Stethoscope. This experiment demonstrates that the NanoStethoscope can detect vibrations on the Angstrom scale at frequencies up to the $\mathrm{kHz}$ range and that it is suitable for submicron spatial analysis of the thermal performance of electronic circuits.

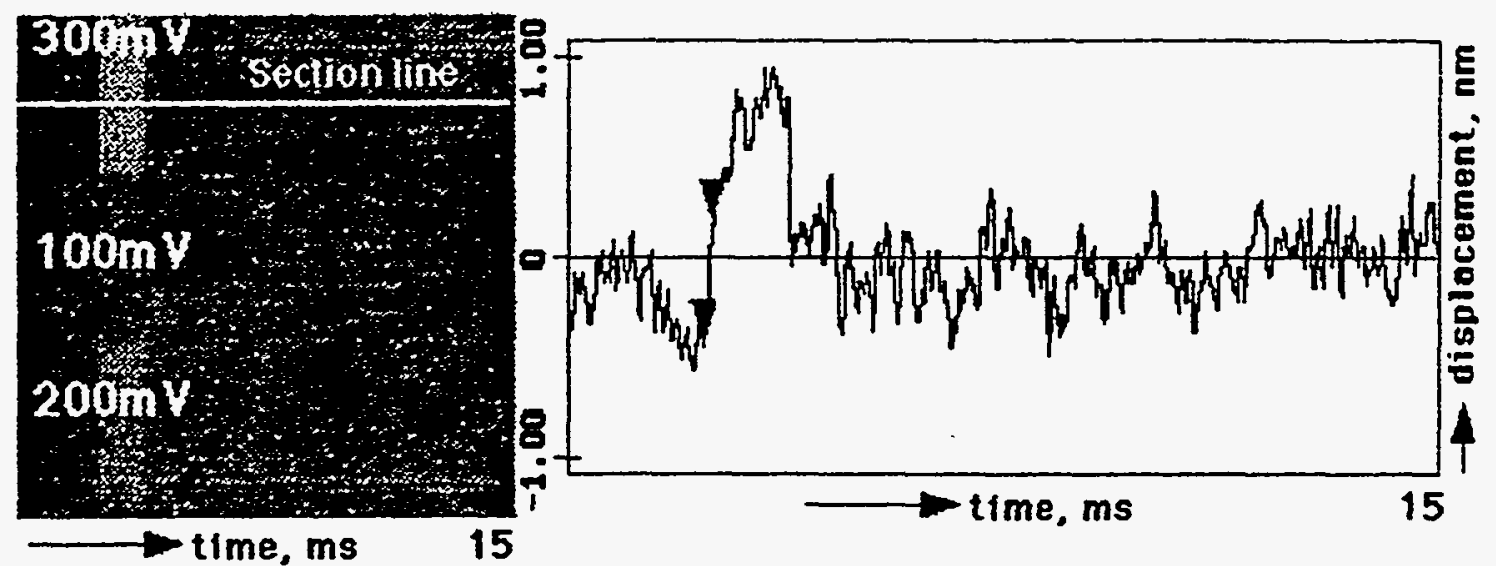

Figure 4. (a) False gray scale image of cantilever displacement for pulses with amplitudes of 300.100 . and $200 \mathrm{mV}$ (from top down in inserted image). (b) Section along horizontal line in the image. Spectrum shows sharp rise of $0.598 \mathrm{~nm}$ to temperature of $-40^{\circ} \mathrm{C}$. 


\subsection{NOISE ANALYSIS IN THE NANO-STETHOSCOPE}

\subsubsection{Biological Systems}

For vibrational analysis of biological systems. the Nano-Stethoscope has been carefully insulated against electrical and acoustic noise and temperature fluctuations. These steps have resulted in rms vibrational noise levels of less than $1 \AA$ for an AFM tip placed onto a biological substrate (E. coli), as shown in Fig. 5.

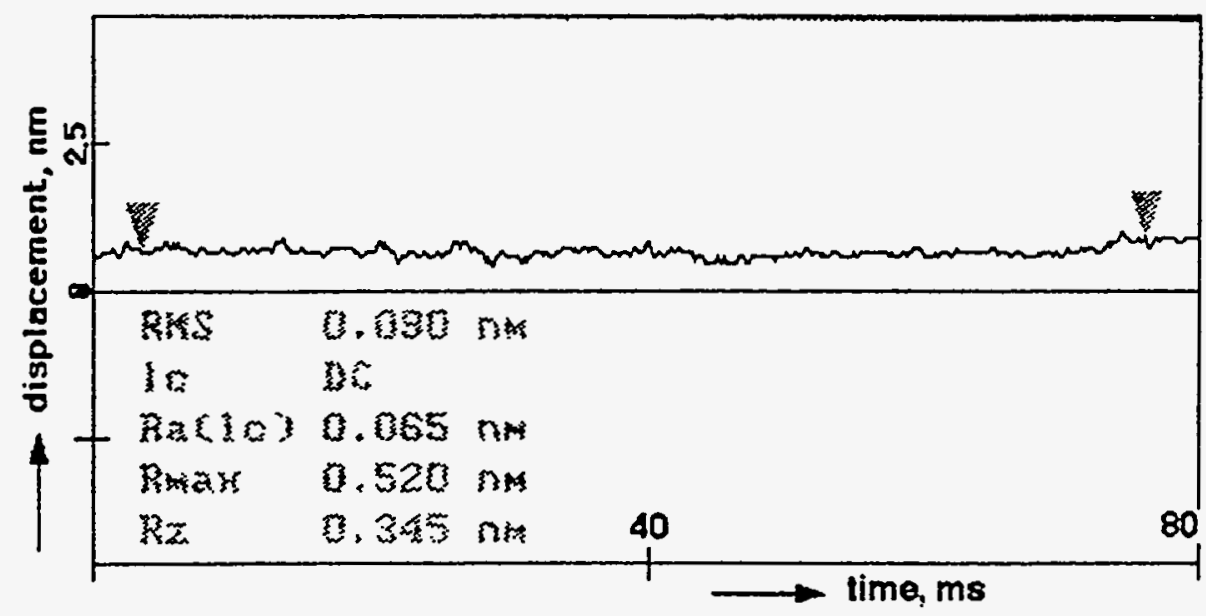

Figure 5. Nano-Stethoscope noise observed by the proposed technique on a biological substrate ( $E$. coli). Rms value of noise is $0.09 \mathrm{~nm}$, calculated between arrows approximately $70 \mathrm{~ms}$ apart.

\subsubsection{Microelectronic Circuit}

The noise of the instrument in the configuration used to measure mechanical motion induced by electrical current (shown in Fig. 1) increases to $2 \AA \mathrm{ms}$ at high frequency as shown in Fig. 6. presumably because of the electronic cables and devices attached to the Nano-Stethoscope. 

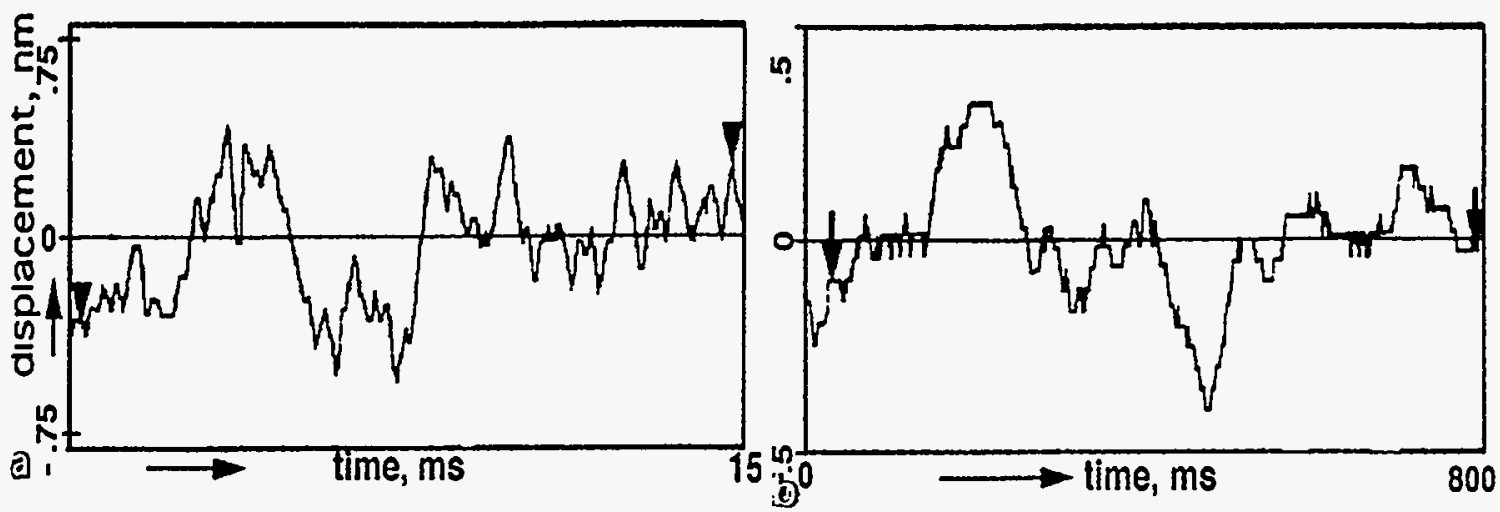

Figure 6. Noise in Nano-Stethoscope with pulse generation electronics attached at (a) high frequency and (b) low frequency. Rms noise is $0.21 \mathrm{~nm}$ in (a) and $0.14 \mathrm{~nm}$ in (b).

\subsection{Conclusions}

We have demonstrated the a new mode of operation of the atomic force microscope in two test systems: a biological system. an emerging shrimp egg nauplius, and a non-biological system. the thermal expansion of metal interconnect lines on a microelectronic circuit.

The detection of Angstrom scale vibrations leads us to believe that it may be possible to use this approach to observe the dynamic processing, in real time, of the replication of the DNA molecule by E. coli DNA Polymerase I. We have considered the feasibility of this application from a theoretical perspective; our current work is directed toward this experimental objective.

\subsection{Acknowledgment}

This work was performed under the auspices of the US DOE at Lawrence Livermore National Laboratory under DOE contract W-7405-ENG-48.

\subsection{References}

${ }^{1}$ M. Salmeron, T. Beebe, J. Odriozola, T. Wilson, D.F. Ogletree, and W. Siekhaus, J. Vac. Sci. Technol. A8, 635 (1990).

2 G. Lee, P.G. Arscott, V.A. Bloomfield, and D.F. Evans, Science 244, 475 (1989).

${ }^{3}$ A. Cricenti, S. Selci, A.C. Felici, R. Generosi, E. Gori. W. Djaczenko, and G. Chiarotti, Science 245, 1226 (1989).

${ }^{4}$ S. Selci, A. Cricenti, A.C. Felci, R. Generosi, E. Gori, W. Djacenko, and G. Chiarotti, J. Vac. Sci. Technol. A8, 642 (1990).

5T.P. Beebe, Jr., T.E. Wilson, D.F. Ogletree, J.E. Katz, R. Balhorn, M.B. Salmeron, and W.J. Siekhaus, Science 243, 370 (1988).

6D. Keller, C. Bustamante, and R.W. Keller, Proc. Natl. Acad. Sci. 86, 5356 (1989). 
${ }^{7}$ C. Bendixen, F. Besenhacher, E. Lacgsgaard. I. Stensgaard. B. Thomsen. and O. Westgaard, J. Vac. Sci. Technol. A8. 703 (1990).

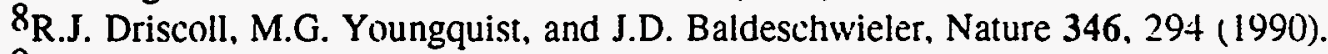

${ }^{9}$ B. Barris, U. Knipping, S.M. Lindsay, L. Nagahara, and T. Thundat, Biopolymers 27. 1691 (1988).

10 S.M. Lindsay and B. Barris, J. Vac. Sci. Technnol. A6, $5+4$ (1988).

${ }^{11}$ S.M. Lindsay. L.A. Nagahara. T. Thundat, U. Knipping. R.L. Rill, B. Drake, C.B. Prater. A.L. Wiesenhorn, S.A.C. Gould, and P.K. Hansma, J. Biomol. Struct. Dyn. 7. 279 (1989). ${ }^{12}$ S.M. Lindsay, L. Nagahara, T. Thundat, and P. Oden, J. Biomol. Struct. Dyn. 7, 289 (1989).

${ }^{13}$ S.M. Lindsay, T. Thundat, L. Nagahara, U. Knipping, and R. Rill, Science 244, 1063 (1989).

14T. Thundat, L.A. Nagahara, P Oden, and S.M. Lindsay, J. Vac. Sci. Technol. A8. 645 (1990).

15D.D. Dunlap and C. Bustamante, Nature 242. 204 (1989).

16P.G. Arscott. G. Lee, V.A. Bloomfield. and D.F. Evans. Nature 339. 484 (1989).

17 M.J. Allen. M. Balooch, S. Subbiah, RJ. Tench, W. Siekhaus, and R. Balhorn, Scanning Microsc. 5 , 625 (1991).

${ }^{18}$ W.M. Heckl. D.P.E. Smith. G. Binnig, H. Klagges, T.W. Hansch, and J. Maddocks. Proc. Natl. Acad. Sci. 88. 8003 (1991).

${ }^{19}$ C. Bustamante. J. Vesenka, C.L. Tang, W. Rees, M. Guthold, and R. Keller. Biochem. 31. 22 (1992).

${ }^{20}$ T. Thundat, D.P. Allison, R.J. Warmack, and T.L. Ferrell, Ultramicroscopy 42-44, 1101 (1992).

${ }^{21}$ T. Thundat, R.J. Warmack, D.P. Allison, L.A. Bottomley, A.J. Lourenco, and

T.L. Ferrell, J. Vac. Sci. Technol. A 10. 630 (1992).

${ }^{22}$ H.G. Hansma, R.L. Sinsheimer, M.Q. Lin, and P.K. Hansma, Nucleic Acids Res. 20. 3585 (1992).

${ }^{23}$ H.G. Hansma, M. Bezanilla, F. Zenhausern, M. Adrian, and R.L. Sinsheimer, Nucleic Acids Res. 21, 505 (1993).

${ }^{24}$ M. Allen. M. Balooch, S. Subbiah, R.J. Tench, and W.J. Siekhaus, Ultramicroscopy 42. 1049 (1992).

25 J.F. Holzrichter and W.M. Heckl, Nonlinear Optics 1. 53 (1992).

26 A. Keaton, J.F. Holzrichter, W.J. Siekhaus, and R. Balhorn. UCRL-JC-114924.

${ }^{27}$ H.G. Hansma, J. Vesenka, C. Siegerist, G. Kelderman, H. Morrett, R.L. Sinsheimer. V. Elings, C. Bustamante, and P.K. Hansma. Science 256, 1180 (1992). 